\title{
3 Year simvastatin treatment and lens nuclear back scattering
}

\author{
Wen Qian, Per G Söderberg, Enping Chen, Karin Magnius, Bo Philipson
}

Research Laboratory, St Erik's Eye Hospital, Karolinska Institutet, Stockholm, Sweden W Qian

P G Söderberg

E Chen

K Magnius

B Philipson

Correspondence to: Wen Qian, Research

Laboratory, St Erik's Eye

Hospital, S-112 82

Stockholm, Sweden

wen.qian@brain.ste.ki.se

Accepted for publication 13 January 2000

\begin{abstract}
Aim-To determine if 3 year treatment of hypercholesterolaemia with simvastatin causes an increase of lens nuclear back scattering.

Methods-160 patients with hypercholesterolaemia in the Scandinavian Simvastatin Survival Study (4S) were followed for 3 years. Half (80) of the patients took simvastatin and half $(80)$ received placebo. The lens was photographed with a Topcon SL-45 slit lamp camera at the beginning and at 1 year intervals. A common lens nuclear area was used for measuring lens nuclear back scattering.

Results-Nuclear back scattering increased with age and there was more pronounced scattering in women than in men. Lens nuclear back scattering did not differ significantly between the simvastatin and placebo groups, but the power was low (0.2). Lens nuclear back scattering increased during the study period independently of baseline back scattering, age, and sex for both groups.

Conclusion-Although no significant difference was found between the simvastatin and placebo groups, the currently available data are insufficient for exclusion of the possibility that taking simvastatin during a 3 year period increases nuclear back scattering. However, a possible minor increase of nuclear back scattering is clinically irrelevant considering known beneficial effects of simvastatin on coronary heart disease.
\end{abstract}

(Br F Ophthalmol 2000;84:512-516)

Hypercholesterolaemia is a main risk factor for coronary heart disease. ${ }^{1}$ A group of new drugs, HMG-CoA reductase inhibitors, are commonly presented for patients with hypercholesterolaemia. Simvastatin is one of the HMGCoA reductase inhibitors. Simvastatin effectively reduces the cholesterol level, ${ }^{2}{ }^{3}$ and

subjective, and conventional slit lamp photography has limited depth of focus, causing a partly blurred image. ${ }^{15}$ Moreover, both techniques have a poor reproducibility. ${ }^{15}$ Consequently, the power of the outcome of the above mentioned studies is limited and was never estimated.

Slit lamp microscope photography of the lens with Scheimpflug projection has been recommended by the World Health Organisation as a suitable technique for studies of drug effects on the lens. ${ }^{16}$ With this technique a photograph which is in focus from the anterior surface of the cornea to the posterior surface of the lens can be obtained. Further, there is a built in five step grey scale reference. Measurement of the lens image together with the grey scale reference on the photograph provides quantitative information of the lens density. ${ }^{15}$

In studies by Schmidt et $a l,^{1011}$ the ocular lens was photographed by Scheimpflug photography. The image of the lens was measured by linear densitometry in the Scheimpflug photograph along three lines: the optical axis, $1 \mathrm{~mm}$ above, and $1 \mathrm{~mm}$ below the optical axis. In these studies, the density of the cornea was used as an external standard for calibration of a densitometric reading of the lens. Theoretically the back scattering from the cornea could not be constant over time. Therefore, the reliability of the cornea as a standard is questionable.

In the present work, lens nuclear back scattering was measured in a common lens nuclear area (CNA) of the lens photograph. ${ }^{17}$ This method gives a calibrated reading of nuclear back scattering with reasonable precision. ${ }^{18}$

The purpose of the present study was to determine if 3 years of treatment with simvastatin causes an increase in nuclear back scattering in patients with hypercholesterolaemia.

\section{Materials and methods}

long term treatment with simvastatin improves disease. ${ }^{4}$

Cataract has been observed in dogs treated with simvastatin, ${ }^{5}$ but a number of investigations have failed to demonstrate a significant risk of cataract in the human lens..$^{6-14}$ Several 2 year studies reported that simvastatin does not cause significant increase of lens opacity. ${ }^{7-11}$ Similar results were also obtained in 3 year clinical trials, ${ }^{12}{ }^{13}$ and in one 5 year study. ${ }^{14}$

These studies were generally based on slit lamp examination and conventional slit lamp photography for evaluation of lens opacity. ${ }^{7-14}$ Slit lamp examination is qualitative and
VARIABLES CONSIDERED AND STUDIED

All patients underwent a routine ophthalmological examination which included standardised Bailey-Lovie visual acuity with best refraction, contrast sensitivity function using the Vistech VCTS 6000 contrast sensitivity test, retroillumination photography at maximal mydriasis using a Neize-CRT camera, and Scheimpflug photography at maximal mydriasis using a Topcon SL-45 rotating slit lamp camera. The examination was performed at baseline and after 1, 2, and 3 years of observation. The current paper includes an analysis of the nuclear back scattering data documented 


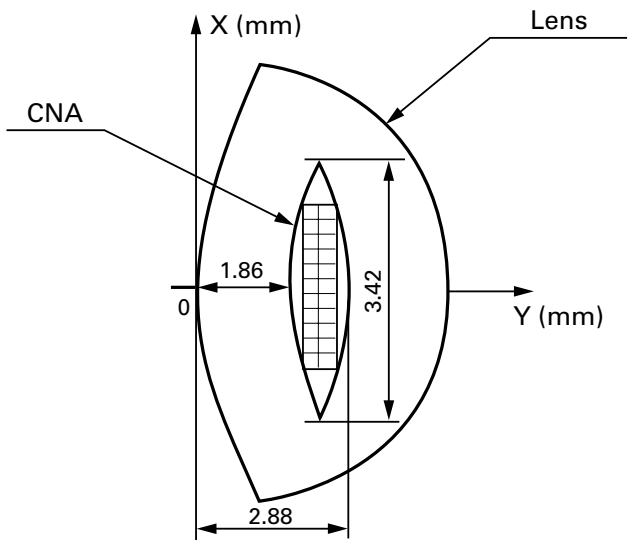

Figure 1 Schematic drawing of a lens image. The area enclosed by the parabolas was defined as a common lens nuclear area (CNA). The rectangle within the CNA was selected for photometry.

by Scheimpflug photography. Explanatory variables studied were simvastatin treatment, time of treatment, age, sex, and baseline nuclear back scattering.

NUCLEAR BACK SCATTERING MEASUREMENT The lens was photographed with slit lamp microscopy with Scheimpflug projection (SL45, Topcon, Japan). All photographs were taken at a slit orientation of $90^{\circ}$. The film (TX 5063, Kodak, USA) was developed according to a standard procedure. ${ }^{19}$

The photograph was measured with a photometer. ${ }^{20}$ In our previous study, a CNA was defined for optimal measurement of lens opacity. ${ }^{17}$ The CNA was used for photometry in this study. Considering the spot size used in the photometer and to facilitate the measurement, a rectangle within the CNA was selected for measurement of nuclear back scattering (Fig 1).

Table 1 Exclusion criteria for the lens evaluation

Diabetes mellitus or fasting blood glucose $\geqslant 7.8 \mathrm{mmol} / 1(140 \mathrm{mg} / \mathrm{dl})$

Concurrent use of antipsychotics, allopurinol, and/or corticosteroids

Hypocalcemia or conditions or therapy which might increase the risk of developing lens opacity

Dry eye syndrome (keratoconjunctivitis sicca)

History of diathesis for angle closure glaucoma

History of severe blunt or penetrating eye trauma

History of laser or intraocular surgery

History of exposure to therapeutic doses of $x$ ray irradiation to the head

Regular use of antiglaucoma medication or ocular topical corticosteriods

Allergy to topical mydriatics

Bilateral aphakia

Arc welders and glass blowers

Cataract extraction surgery likely to be necessary within 3 years of enrolment

Table 2 Information of patients lost

\begin{tabular}{lll}
\hline & Reason & Number \\
\hline Patients lost before 1 year examination & Death & 1 \\
& Unwilling to continue & 3 \\
& Stopped because of adverse experience & 2 \\
Patients lost before 2 year examination & 3 \\
& Death & 3 \\
& Unwilling to continue & 6 \\
& Stopped because of adverse experience & 1 \\
& Taking corticosteroids & 1 \\
Patients lost before 3 year examination & Death & 1 \\
& Unwilling to continue & 2 \\
& Stop participating in the study because & \\
& of adverse experience & 1
\end{tabular}

${ }^{\star}$ In the present study adverse experience includes dizziness, myocardial infection, diabetes, angina pectoris, insomnia, proctocolectomy, carcinoma, dyspepsia, and skin disorder.
The photometric reading was converted to grey scale level by using the five step grey scale reference on the same photograph. ${ }^{18}$ The converted value was considered as the intensity of back scattering of the lens nucleus.

A primary analysis of the precision of the measurement method ${ }^{17} 21$ demonstrated that the variability between eyes of an individual, among photographs within an eye, and measurements within photograph is negligible compared with the variation from one occasion to another within an individual. Therefore, only one eye in each individual, one photograph from each eye, and one measurement of each photograph was considered. The eye measured was selected randomly.

\section{Patients}

RECRUiTMENT

Patients with hypercholesterolaemia that had been selected for the Swedish substudy of the Scandinavian Simvastatin Survival Study $(4 S)^{4}$ were randomised with regard to age, sex, and simvastatin treatment (initially $20 \mathrm{mg} /$ day, after 6-8 weeks $20 \mathrm{mg} /$ day if cholesterol level was $\leqslant 5.2 \mathrm{~mol} / 1$ and $40 \mathrm{mg} /$ day if cholesterol level was $>5.2 \mathrm{~mol} / \mathrm{l})$. Thus the age and sex distribution were comparable for both treatment categories. Simvastatin treatment was blind to the patient and everyone carrying out the study.

\section{EXCLUSION}

Patients recruited were sent for baseline examination to one experienced ophthalmologist who carried out all the Scheimpflug photography and clinical examinations. Patients with any of the exclusion criteria of the lens evaluation (Table 1) were excluded.

INCLUSION

A total of 184 patients were included in the study.

TIME CROSS SECTIONS FOR OBSERVATION

The study was designed to include baseline and the 1, 2, and 3 year observations. In the present study the interest was focused on the long term effect and consequently only baseline, 2 , and 3 years of observation were analysed.

\section{DROPOUTS}

Of the included patients, six were lost before the 1 year examination, 13 were lost before the 2 year examination, and five were lost before the 3 year examination. The reasons for dropout are given in Table 2. The median age of the dropout patients was 61 years, and among them there were two women and 22 men. None of the patients dropped out because of lens opacity.

The characteristics of the remaining 160 patients are given in Table 3.

\section{STATISTICAL ANALYSIS}

The study was designed to evaluate the effect of treatment and treatment time with an analysis of variance. ${ }^{22}$ The effect of age and sex on 
Table 3 Characteristics of the study group

\begin{tabular}{lllll}
\hline & & & \multicolumn{2}{c}{ Age (years) } \\
\cline { 5 - 5 } Groups & Sex & $\begin{array}{l}\text { Number of } \\
\text { patients }\end{array}$ & Median & Range \\
\hline Simvastatin & Male & 62 & 60 & $(38 ; 70)$ \\
& Female & 18 & 59 & $(50 ; 69)$ \\
Placebo & Male & 66 & 62 & $(46 ; 70)$ \\
& Female & 14 & 61 & $(57 ; 69)$ \\
\hline
\end{tabular}

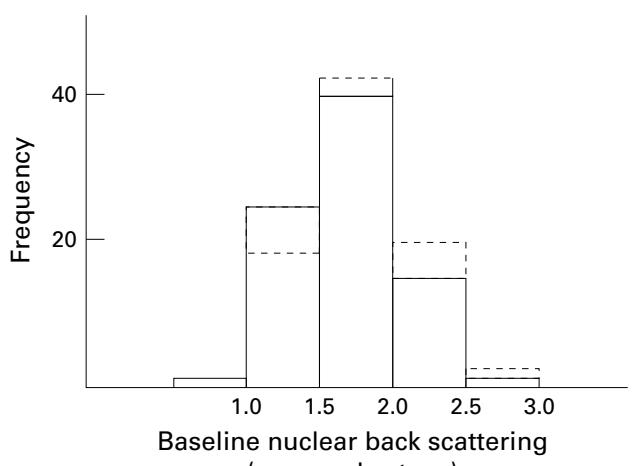

(grey scale steps)

Figure 2 Estimated frequency distribution for the intensity of baseline nuclear back scattering light in the simvastatin (solid line) and placebo groups (broken line).

lens nuclear back scattering was analysed by multiple regression. ${ }^{23}$ The significance level was set to 0.05 and the confidence coefficient was set to 0.95 .

\section{Results}

BASELINE NUCLEAR BACK SCATTERING

A frequency distribution of the baseline nuclear back scattering in the simvastatin and placebo group is shown in Figure 2. The baseline nuclear back scattering expressed as the $95 \%$ confidence interval for the mean was $1.69 ; 1.80$ grey scale unit (GSU). Despite randomisation, the nuclear back scattering in the simvastatin group had slightly lower baseline than the placebo group (Fig 2).

The effect of age and sex on lens nuclear back scattering was analysed by multiple regression ${ }^{23}$ of the baseline data considering all patients in both treatment groups. The 95\% confidence intervals for the regression coefficients was $(0.038( \pm 0.006))$ GSU/year and $(-0.160( \pm 0.096))$ GSU for age and sex, respectively. Since neither of the intervals includes zero, age and sex have a statistically significant impact on lens nuclear back scatter-

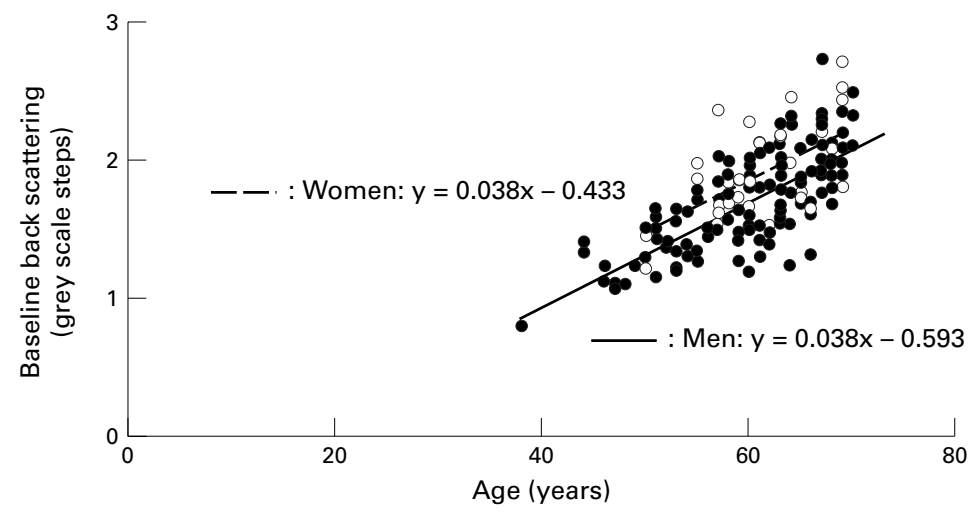

Figure 3 Baseline nuclear back scattering light as a function of age and sex (men: solid symbol and women: open symbol). ing. It was thus found that the intensity of nuclear back scattering increases with increasing age and is more pronounced in women than in men (Fig 3).

SIMVASTATIN VERSUS PLACEBO

The intensity of lens nuclear back scattering was compared between the simvastatin and placebo groups using an analysis of variance according to a mixed model (see Appendix). The result is given in Table 4 .

TREATMENT EFFECT

There is a trend for higher increase of nuclear back scattering in the simvastatin group than in the placebo group (Fig 4), but this difference was not significant (Table 4: treatments).

TIME EFFECT

The intensity of lens nuclear back scattering increases significantly during 3 years of observation (Fig 4, Table 4: times). There was no statistically significant difference in the increase of lens nuclear back scattering with time between simvastatin and placebo (Table 4: Int $(\operatorname{Tr}-\mathrm{T}))$.

A $95 \%$ confidence interval for the difference in nuclear back scattering between 3 years and at baseline was $(82( \pm 41)) \times 10^{-3}$ and $(45( \pm 36))$ $\times 10^{-3} \mathrm{GSU}$ for simvastatin and placebo groups, respectively. The average increase of nuclear back scattering in the simvastatin group is greater than that in the placebo group, but this difference was not significant (Table 4: Int $\mathrm{Tr}-$ $\mathrm{T})$. However, the $\beta$ error for the test was 0.8 , indicating an $80 \%$ risk that the groups differ although the statistical test does not confirm this. The reason for the limited power is the substantial variation of nuclear back scattering from one occasion to another within individuals ${ }^{17}$ in relation to sample size and signal.

\section{BASELINE DEPENDENT INCREASE OF NUCLEAR} BACK SCATTERING

In order to elucidate a possible baseline dependent increase of nuclear back scattering in the simvastatin group, the difference of nuclear back scattering between 3 years and at baseline was calculated individually in both groups. The data were plotted as a function of baseline in a scatter plot (Fig 5). The scatter plot shows that the increase of lens nuclear back scattering was independent of baseline for both groups.

AGE AND SEX DEPENDENT 3 YEAR INCREASE OF NUCLEAR BACK SCATTERING

Multiple regression ${ }^{23}$ was employed to determine a possible age and sex dependence in the 3 year increase of nuclear back scattering.

Multiple regression shows that the 3 year increase of back scattering was also independent of age and sex for both groups. The estimated $95 \%$ confidence interval for the regression coefficients was $2( \pm 51) \times 10^{-4} \mathrm{GSU} /$ year and $-50( \pm 820) \times 10^{-4}$ GSU for age and sex respectively. 
Table 4 Comparison of nuclear back scattering of light in the crystalline lens between systemic treatment with simvastatin and placebo

\begin{tabular}{|c|c|c|c|c|}
\hline $\begin{array}{l}\text { Sources of } \\
\text { variation }\end{array}$ & $\begin{array}{l}\text { Degree of } \\
\text { freedom }\end{array}$ & $\begin{array}{l}\text { Mean square } \\
(G S U)^{2}\end{array}$ & Expected mean square & $\begin{array}{l}\text { Test statistic } \\
\left(F_{f l: f: 0.095}\right)\end{array}$ \\
\hline Treatments & 1 & 0.3327 & $\sigma_{\varepsilon}^{2}+c \sigma_{B}^{2}+b c \kappa_{a}^{2}$ & $0.93(3.84)$ \\
\hline Times & 2 & 0.1635 & $\sigma^{2^{2}}+\sigma^{2}+a b \kappa^{2}$ & $10.64(3.00)$ \\
\hline Patients & 158 & 0.3582 & $\sigma_{\varepsilon}^{2}+c \sigma_{B}^{2}$ & \\
\hline Int $(\mathrm{Tr}-\mathrm{T})$ & 2 & 0.0137 & $\sigma_{\varepsilon}^{2}+\sigma_{\mathrm{B} \gamma}^{2}+b \kappa_{\alpha \gamma}^{2}$ & $0.89(3.00)$ \\
\hline Int $(P-T)$ & 316 & 0.0154 & $\sigma_{\varepsilon}^{z_{z}^{2}}+\sigma_{\mathrm{B} \gamma}^{2^{\mathrm{B} \gamma}}$ & \\
\hline
\end{tabular}

Int $(\mathrm{Tr}-\mathrm{T})=$ interaction between treatments and time points. Int $(\mathrm{P}-\mathrm{T})=$ interaction between patients and time points. $\kappa^{2}=$ a factor corresponding to the systematic shift because the indexed fixed source; $\alpha=$ treatment; $\gamma=$ time points. $\sigma^{2}=$ The expected variance for the indexed random source; $\mathrm{B}=$ patients, $\varepsilon=$ measurement error. $\mathrm{a}=$ The number of treatments $=2 ; \mathrm{b}=$ the number of patients within a treatment $=80 ; \mathrm{c}=$ the number of time points for each patient $=3$.

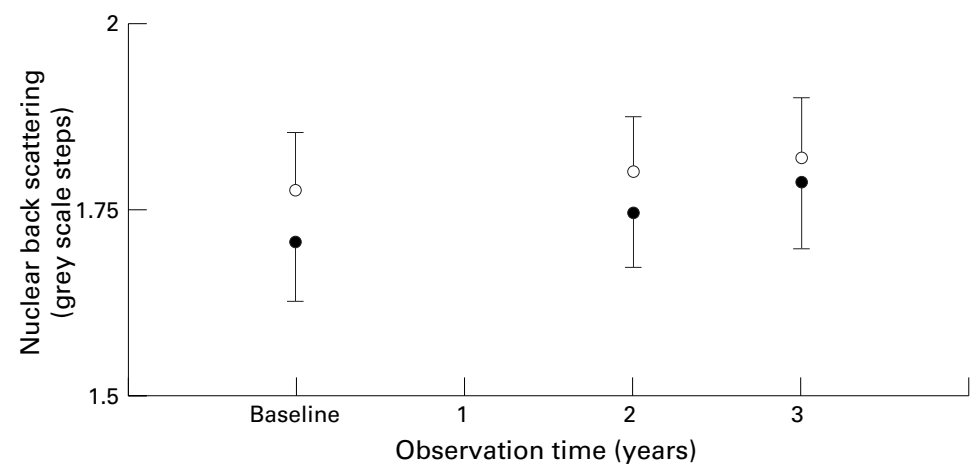

Figure 4 Crystalline lens nuclear back scattering of light from baseline to 3 years' treatment with simvastatin (solid symbol) and placebo (open symbol). Bars are $95 \%$ confidence intervals for the means ( $n=80$ for each group).

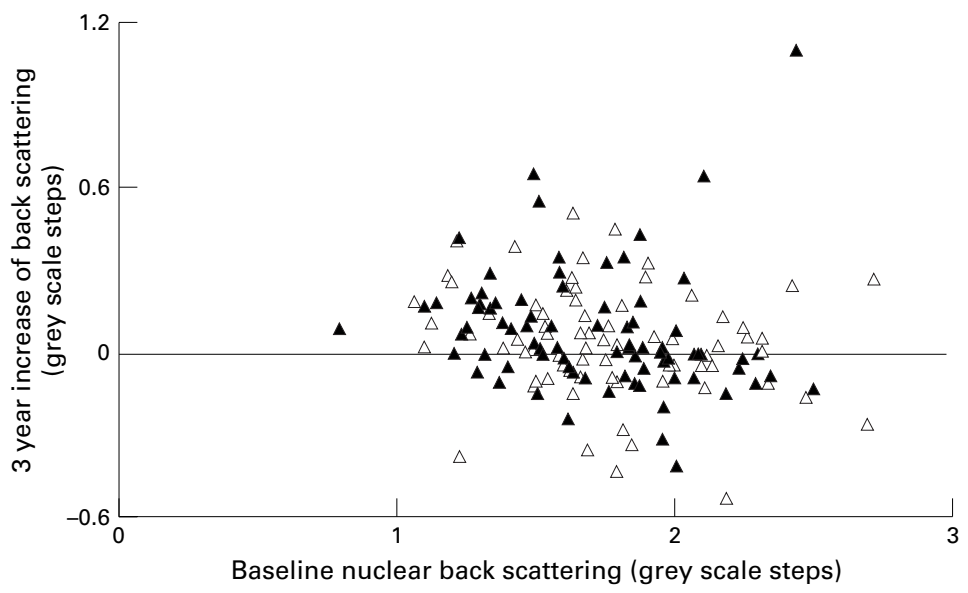

Figure 53 Year increase of nuclear back scattering as a function of baseline for simvastatin (solid symbol) and placebo (open symbol).

\section{Discussion}

Simvastatin is one of the HMG-CoA reductase inhibitors, and clinical trials have demonstrated its beneficial effect on hypercholesterolaemia. ${ }^{2-4}$ In the present study, the possible side effect of simvastatin on human lens nuclear opacity was investigated.

The finding that lens nuclear back scattering increases with age is consistent with earlier findings. ${ }^{24-26}$

The estimated $95 \%$ confidence interval for the regression coefficient for sex $((-0.256$; -0.064) GSU) implies that among individuals with high serum cholesterol females have more intense nuclear back scattering than males. This sex difference indicates that sex should be randomised or stratified in epidemiological studies on nuclear opacification.
The lack of a significant difference in nuclear opacity after 3 years between the simvastatin and placebo groups is consistent with previous 3 year follow up studies, ${ }^{12}{ }^{13}$ and a recent 5 year follow up study. ${ }^{14}$ In these studies no attempt was made to estimate the power of the conclusion.

Although no significant difference was found in the present study, there is a trend (Fig 4), indicating that the rate of nuclear back scattering increase is higher for the simvastatin group than for placebo, and the mean nuclear back scattering change for the 3 year period was higher for simvastatin than for placebo.

The 3 year increase of nuclear back scattering in the placebo group was on average 0.045 GSU. If the threshold for a clinically acceptable additional increase in nuclear back scattering over a 3 year period is set to 1 year's normal increase $(0.045 / 3=0.015 \mathrm{GSU})$, the increase of nuclear back scattering caused by simvastatin in 3 years should be ideally less than 0.06 GSU $(0.045+0.015)$. The mean difference of 3 year increase between the simvastatin and placebo groups, estimated as a CI (0.95) was $(-0.017 ; 0.092) \mathrm{GSU}(\mathrm{df}=158)$. Since 0.015 $(0.045 / 3)$ GSU is included in $(-0.017 ; 0.092)$ GSU, the current study does not exclude that simvastatin could be a risk factor that speeds up the increase in nuclear back scattering.

However, the effect of an increase in nuclear back scattering of 0.015 GSU on visual function is unknown. Further, for detection of such a small signal (0.015 GSU) with a power of 0.8, a large sample size $(n-6000)$ is required. Considering the beneficial effects of simvastatin on patients with coronary heart disease, ${ }^{4}$ the trend for an increase of nuclear back scattering observed in the current study (Fig 4) is probably clinically insignificant.

There are several methods available for quantitative measurement of lens nuclear opacity. ${ }^{27-29}$ The sample size in this study was set by $4 \mathrm{~S}$ protocol according to one of the methods. ${ }^{27}$ In this study we would develop a method for calibration of measurements using the internal grey scale reference in the Topcon SL-45 camera, and define a common nuclear area (CNA) to optimise documentation and evaluation of nuclear opacity.

The internal grey scale reference, which is built in the Topcon SL-45 camera, is considered to be stable and constant. Moreover, the scale of the internal reference corresponds to the range of the lens nuclear density. Therefore, the internal reference was selected for the calibration of measurements in this study. The precision of the calibration was estimated to $2 \% .{ }^{18}$

There is a variability in location and size of the nuclear area among lenses. Moreover, the border between the cortex and nucleus is usually indistinguishable on Scheimpflug image, especially for the posterior part of the nucleus, because of the light attenuation. The established CNA provides an integral sample for documentation and evaluation of nuclear density since it is the largest area within the lens nucleus for which the risk of wrongly including the anterior and posterior cortex is $2.5 \% .{ }^{17}$ In addition, the CNA can be used universally for 
all patients in the age range of $50-80$ years. Therefore, use of the CNA will contribute to improve the precision for documentation of lens nuclear opacity, and facilitate the measurement procedure. ${ }^{17}$

Scheimpflug photography has been proved as a suitable tool for studying the nuclear opacity of the lens, as the nuclear opacity is homogeneously distributed around the anteriorposterior pole..$^{30-37}$ Consequently, any optical section through the anterior-posterior pole could be used as a reliable sample of the whole nucleus. Therefore, the nuclear back scattered light is a measurement factor in this study.

The precision in estimation of increase of nuclear back scattering within patients would have increased if the back scattering of the two eyes for each patient had been averaged. However, an analysis showed that the variation caused by the variability of eyes within patients and measurement error is small in relation to the variation on different occasions within individuals. Therefore, the power of the finding that there was no difference in 3 year increase of back scattering between simvastatin and placebo groups would have changed only minimally if the back scattering of the two eyes had been averaged.

The present study was conducted to examine a possible adverse effect on the human lens caused by the cholesterol lowering drug simvastatin. We found that there was no significant increase in lens nuclear back scattering caused by simvastatin but the power of this conclusion was low. It is therefore desirable to follow the current cohort for a longer period.

The authors would like to thank Professor Bo Lindström for valuable suggestions on the statistical analysis, and Dr John Marriam for correcting linguistic error.

\section{Appendix}

The data were analysed with an analysis of variance for a mixed model ${ }^{22}$ :

$\mathrm{x}_{\mathrm{ijk}}=\mu+\alpha_{\mathrm{i}}+\mathrm{B}_{\mathrm{i}(\mathrm{i})}+\gamma_{\mathrm{k}}+(\alpha \gamma)_{\mathrm{ik}}+(\mathrm{B} \gamma)_{\mathrm{jk}(\mathrm{i})}+\varepsilon_{(\mathrm{ijk})}$

Here, each grey scale value, $x_{\mathrm{ijk}}$, equals the sum of the expected total mean, $\mu$, a term for the fixed effect between treatment groups, $\alpha_{\mathrm{i}}$ (i $=1 \ldots \mathrm{a}, \mathrm{a}=2)$, a term for the random variation among patients within a group, $B_{j(i)}(j=1 \ldots b$, $b=80$ ), a term for the fixed effect among different time points, $\gamma_{k}(k=1 \ldots c, c=3)$, a term for interaction between treatment groups and time points, $(\alpha \gamma)_{\mathrm{ik}}$, a term for interaction between patients and time points, $(\mathrm{B} \gamma)_{\mathrm{jk}(\mathrm{i})}$, and a term for random error of measurement, $\varepsilon_{(\mathrm{ijk})}$.

1 The Expert Panel. Report of the national cholesterol education program expert panel on detection, evaluation, and treatment of high blood cholesterol in adults. Arch Intern Med 1988;148:36-69. [Review] Cardiology 1990;77(Suppl 4):58-65

2 Bilheimer DW. Long-term clinical tolerance of lovastatin and simvastatin. [Review] Cardiology 1990;77(Suppl 4):58-65.

3 Jones PH. Lovastatin and simvastatin prevention studies. [Review] Am 7 Cardiol 1990;66:39B-43B.

4 The Scandinavian Simvastatin Survival Study Group. Randomised trial of cholesterol lowering in 4444 patients with coronary heart disease: the Scandinavian Simvastatin Survival Study (4S). Lancet 1994;344:1383-1389 (No 8934).

5 Gerson RJ, MacDonald JS, Alberts AW, et al. On the etiology of subcapsular lenticular opacities produced in dogs receiving HMG-CoA reductase inhibitors. Exp Eye dogs receiving $\mathrm{HM}$

6 Harris ML, Bron AJ, Brown NAP, et al. Absence of effect of simvastatin on the progression of lens opacities in a
randomsed placebo controlled study. Br $\mathscr{f}$ Ophthalmol randomsed placebo
7 Boccuzzi SJ, Bocanegra TS, Walker JF, et al. Long-term safety and efficacy profile of simvastatin. Am 7 Cardiol 1991;68:1127-31.

8 Leclercq V, Harvengt C. Simvastatin (MK 733) in heterozygous familial hypercholesterolemia: a two-year trial. Int f Clin Pharmacol 1989;27:76-81.

9 Lundh BL, Nilsson SE. Lens changes in matched normals and hyperlipidemic patients treated with simvastatin for 2 years. Acta Ophthalmol (Copenh) 1990;68:658-60.

10 Schmidt J, Schmitt C, Hockwin O. No lens changes caused by simvastatin results from a prospective drug safety study. Lens Eye Toxic Res 1990;7:643-50.

11 Schmidt J, Schmitt C, Hockwin O, et al. Ocular drug safety and HMG-CoA-reductase inhibitors. Ophthalmic Res 1994;26:352-60.

12 Behrens-Baumann W, Thiery J, Wieland E, et al. 3-Hydroxy3-methylglutaryl coenzyme A reductase inhibitor simvastatin and the human lens. Clinical results of a 3-year follow-up. Arzneim-Forsch/Drug Res 1992;42:1023-4.

13 Molgaard J, Lundh BL, von Schenck H, et al. Long-term efficacy and safety of simvastatin alone and in combination therapy in treatment of hypercholesterolemia. Atherosclerosis 1991;91(Suppl):S21-8.

14 Pedersen TR, Berg K, Cook TJ, et al. Safety and tolerability of cholesterol lowering with simvastatin over 5 years in the Scandinavian Simvastatin Survival Study (4S). Arch Intern Med 1996;156:2085-92.

15 Dragomirescu V, Hockwin O, Koch $\mathrm{H}$, et al. Development of a new equipment for rotating slit image photography according to Scheimpflug's principle. Interdiscipl Topics Geront 1978;13:1-13.

16 World Health Organisation. Guidelines for the clinical investigation of anticataract drugs in senile cataract. Copenhagen: WHO Regional Office for Europe, 1985.

17 Qian W, Söderberg PG, Chen E, et al. A common lens nuclear area in Scheimpflug photographs. Eye 1993;7:799 804.

18 Qian W, Söderberg PG, Chen E, et al. Evaluation of gray scale steps on Scheimpflug photographs. Acta Ophthalmol 1993;71:79-84.

19 Hockwin O, Dragomirescu V, Laser H. Measurements of lens transparency or its disturbances by densitometric mage analysis of Scheimpflug photography. Graefes Arch Clin Exp Ophthalmol 1982;219:255-62.

20 Lindström B, Philipson B. Microdensitometer system for microradiography. Histochemie 1969;17:187-93.

21 Qian W, Söderberg PG, Lindström B, et al. Spatial distribution of back scattering in the nuclear area of the non-cataractous human lens. Eye 1994;8:524-9.

22 Bennett C, Franklin N. Analysis involving both types of classification. In: Statistical analysis in chemistry and the chemical industry. New York: John Wiley, 1963; chap 7.63.

23 Wonnacott TH, Wonnacott RJ. Multiple regression. In: Introductory statistics. New York: John Wiley, 1990;v 5,chap 13.

24 Sasaki K, Shibata T. Age-related changes of lens transparency: image analysis by photographic sensitometry. In: Henkind P, ed. XXIV International Congress of Ophthalmology. Philadelphia: JB Lippincott, 1983.

25 Bosem ME, Sample PA, Martinez GA, et al. Age-related changes in the human lens: a comparison of Scheimpflug photography and lens density index. F Cataract Refract Surg 1994;20:70-3.

26 Kashima K, Trus BL, Unser M, et al. Aging studies on normal lens using the Scheimpflug slit-lamp camera. Invest Ophthalmol Vis Sci 1993;34:263-9.

27 Chylack LT Jr, Rosner B, Cheng HM, et al. Sources of variance in the objective documentation of human cataratous change with Topcon SL-45 and Neitz-CTR retroillumination photography and computerized image analysis. Curr Eye Res 1987;6:1381-9.

28 Chen T, Mayer H, Bates S, et al. Inter-and intra-operator correlation study of SL-45 lens photography. Lens Res 1988;5:43-54

29 Wolfe JK, Friend J, Singer DM, et al. Assessment of the ability of methods of measuring cataract to detect clinically significant change. Ophthalmic Res 1994;26(suppl 1):5560.

30 Chen SY, Chylack LT Jr, White O. Topcon SL-45 photography, a suitable technique for documenting nuclear but not cortical cataractous change in vivo. Invest Ophthalmol Vis Sci 1985; (suppl)26:119.

31 Sparrow JM, Brown NAP, Ayliffe W, et al. The Oxford clinical cataract classification and grading system. Int Ophthalmol 1986;9:207-25.

32 Brown NA, Bron AJ, Ayliffe W, et al. The objective assessment of cataract. Eye 1987;1:234-46.

33 Datiles MB, Edwards PA, Trus BL, et al. In vivo studies on cataracts using the Scheimpflug slit lamp camera. Invest Ophthalmol Vis Sci 1987;28:707-10.

34 Edwards PA, Datiles MB, Green SD, et al. Reproducibility study on the Scheimpflug cataract video camera. Curr Eye Res 1988;7:955-60.

35 Edwards PA, Datiles MB, Unser M, et al. Computerized cataract detection and classification. Curr Eye Res 1990;9: $517-24$

36 West S, Rosenthal F, Newland HS, et al. Use of photographic techniques to grade nuclear cataract. Invest Ophthalmol Vis Sci 1988;29:73-7.

37 Qian W. Angular change of back scattering of light from the human lens with nuclearcataract. Eye (in press). 